\title{
MODIFICATION OF JUTE WITH SERICIN FOR IMPROVEMENT IN DYEING
}

\author{
Debasish Das ${ }^{1}$, Sumantra Bakshi ${ }^{2}$, Pinaki Bhattacharya ${ }^{3}$
}

Abstract- Jute was modified with hydrolyzed sericin fraction of silk in presence of trisodium citrate as the esterification catalyst following a pad-dry-cure technique. Treatment of jute fabric with $8 \%$ hydrolyzed sericin in presence of $14 \%$ catalyst followed by drying at $950 \mathrm{C}$ for $5 \mathrm{~min}$ and curing at $1400 \mathrm{C}$ for $5 \mathrm{~min}$, produced optimum results in respect of exhaustion and fixation of reactive dyes having chlorotriazine and vinyl salfone reactive groups, when dyeing was accomplished in absence of salt. Colour fastness to wash, light and rubbing of jute for application of reactive dyes remained unaltered for such prior modification with hydrolyzed sericin. IR spectroscopy indicated incorporation of amino acid residues of sericin fraction of silk in polymeric chains of jute via establishment of ester linkages between carboxylic group of the amino acid moiety and hydroxyl groups of the jute cellulose on pad-dry-cure.

Keywords- Reactive dye, jute, sericin, esterification, eco-friendly dyeing

\section{INTRODUCTION}

Jute is an important bio-degradable and naturally renewable fibre used in textiles. [10], [13] It is re-emerging in the international market for production of different value added products like home textiles, technical textiles, shopping bags, handloom and handicraft products etc. apart from its regular use in the area of typical packaging. Among different classes of dyes available for colouration of cellulosic and ligno cellulosic fibres, majority of the dyes and their related processes are associated with the disadvantages of being environmentally suspect, carcinogenic, mutagenic and major pollutants of environment[6]. Use of such dyes has become a matter of deep concern in the light of ever increasing use of those dyes with the increasing magnitude of textiles production. In view of these, reactive class of dyes have been considered to remain a true alternative for colouration of such fibres. The worldwide popularity of reactive dye is due to its ease of method of application, good all round colour fastness properties, colour brightness and availability at reasonable cost.[14] Application process of reactive dyes containing chlorotriazine and vinyl sulphone reactive groups on jute however suffers from the disadvantages of poor exhaustion $(60-65 \%)$ of dye into the fibre and use of large amount of electrolyte that ultimately leads to generation of effluent containing high concentrations of colour and salt. [4],[1] In order to improve the exhaustion and consequent fixation of reactive dye on cellulosic and ligno cellulosic substrates, several attempts including introduction of two identical or different reactive groups per chromophore have been reported in the literature with little or marginal improvement in the exhaustion of such dyes into textile substrates. [3] Reactive dye however when applied on proteineous fibres such as wool and silk, more than $90 \%$ exhaustion of dye is achieved even without necessitating use of any salt for promotion of exhaustion. [5] Incorporation of amino compounds into cotton and jute prior to dyeing is reported to be prospective with respect to improvement of exhaustion of reactive dye into such modified fibers even in absence of salt.[15], [6], [7] It was therefore thought to be of interest to investigate the roles and effects of sericine fraction of silk containing amino acid, when used as a natural modifying agent under the influence of an esterification catalyst to modify jute for improvement of its reactive dyeability. Results of related investigations done on reactive dyeability and related properties of jute fabric samples modified with sericin under the catalytic influence of trisodium citrate are reported in the present article.

\section{MATERIAL}

Jute fabric: Ex- power loom, plain woven jute fabrics with yarns of 191 Tex as warp and 194 Tex as weft having 63 ends/dm and 64 picks/dm and weighing $262 \mathrm{~g} / \mathrm{m} 2$ on the average, were obtained from National Jute Manufacturing Corporation (NJMC), India and used for the present study.

Chemicals used: Analytical reagent grade (AR) EDTA, nonionic surfactant, sodium bicarbonate, hydrochloric acid, sodium hydroxide, anionic agent (sulphonated castor oil), acetic acid, hydrogen peroxide, sodium silicate, trisodium citrate,

\footnotetext{
${ }^{1}$ Department of Jute and Fiber Technology, University of Calcutta, 35 Ballygaunge Circular Road, Kolkata 700019, India

${ }^{2}$ Knitwear Design Department, National Institute of Fashion Technology, Plot 3B Block LA, Salt Lake City, Kolkata 700098, India

${ }^{3}$ Chemical Engineering Department, Heritage Institute of Technology, Chowbaga Road Anandapur, Kolkata, 700107, India
} 
potassium sodium tartrate, common salt, Glouber salt and formic acid were appropriately used in the experiments and analysis as and when required. Ordinary soap of commercial grade were also used.

Reactive dyes used: Procion red M5B (CI Reactive Red 2) and Procion yellow H4C (CI Reactive Yellow 84) were obtained from M/s ATIC Industries Limited, India. Remazol blue R (CI Reactive Blue 19) was obtained from M/s Ashwini International, India. The above dyes were used without any purification for the study.

\section{METHODS}

Degumming of silk: Silk fabric was degummed employing an aqueous solution containing $5 \mathrm{~g} / \mathrm{l}$ nonionic surfactant and $1 \mathrm{~g} / \mathrm{l}$ sodium bicarbonate at a material: liquor ratio of $1: 10$, for a period of $60 \mathrm{~min}$ at $90 \mathrm{oC}$. After degumming the extract was collected and $5 \mathrm{ml} \mathrm{N} / 10$ hydrochloric acid was added per $100 \mathrm{ml}$ of such extract. The acidified extract was subsequently boiled for $10 \mathrm{~min}$ to ensure depolymerisation of poly amino acid residues further by a process of hydrolysis under the influence of a strong mineral acid. The acidified extract was cooled off to room temperature and subsequently filtered. The filtrate so obtained was having a solid content of $9.6 \%(\mathrm{w} / \mathrm{v})$. The $\mathrm{pH}$ of the degumming extract was finally brought to 7 after acid hydrolysis by the addition of requisite amount of sodium carbonate, before it was considered for application on cotton. (Das D, 2014)

Scouring of jute fabric: Scouring of the jute fabric was performed using a solution containing $0.2 \%$ of sodium carbonate and $0.1 \%$ of non-ionic detergent at $60 \mathrm{oC}$ for 30 minutes, where after the fabric was washed with water and dried in air [11].

Bleaching of jute fabric: Bleaching of selected scoured jute samples were done in aqueous media using a solution containing $1.0 \%$ hydrogen peroxide, $1.8 \%$ sodium silicate, $0.4 \%$ sodium carbonate maintaining a mild alkaline condition $(\mathrm{pH} 10)$ in a laboratory jigger machine at a fabric: liquor ratio 1:6 (w/v) for 1 hour at $80 \mathrm{oC}$ [11]. After bleaching the fabric was washed with distilled water, neutralised with dilute acetic acid and finally washed with distilled water, till the washed liquor was neutral.

Application of degumming extract on jute fabric: Application of degumming extract containing sericin on bleached jute fabric was done by padding technique in a laboratory scale two bowl padding mangle. After two successive dipping in the aqueous formulation containing degumming extract, the pressure between the squeezing rollers was adjusted to enable an overall wet pick up of $100 \%$. The aqueous formulation also contained different dosage of trisodium citrate as esterification catalyst for jute as specified. The padded and squeezed jute fabrics were dried at a temperature of $950 \mathrm{C}$ for $5 \mathrm{~min}$ and subsequently oven cured at $140 \mathrm{oC}$ for $5 \mathrm{~min}$, soap washed following ISOII method, washed further with water and air dried. Soap wash following ISOII method was performed by treating the sericin cured fabrics in an aqueous solution containing 5 $\mathrm{g} / \mathrm{l}$ soap at a material : liquor ratio of 1:50 for a period of $45 \mathrm{~min}$ at $50 \mathrm{oC}$ temperature in a wash wheel having rotational speed of $40+5$ revolutions $/ \mathrm{min}$. Those treated samples were then analyzed for weight gain, nitrogen content and other textile related properties. [12] IR spectra of specified jute samples were obtained following $\mathrm{KBr}$ pellet technique described elsewhere [9].

Dyeing of unmodified jute fabric with reactive dye: Applications of Procion red M5B and Procion yellow H4C on unmodified jute fabrics were done following conventional methods at a material: liquor ratio of 1:20 with a starting dye bath temperature of $30 \mathrm{oC}$ and $50 \mathrm{oC}$ respectively. Both the dye baths had a common salt concentration of $70 \mathrm{gm} / \mathrm{l}$ for facilitating exhaustion of dyes into fibre substrates. Fixation of (dichlorotriazenyl) Procion red M5B and (monochlorotriazenyl) Procion yellow $\mathrm{H} 4 \mathrm{C}$ were achieved after 40 minutes of dyeing at dye bath temperatures of $30 \mathrm{oC}$ and $80 \mathrm{oC}$ respectively. Fixation of such reactive dyes were commonly effected employing $10 \mathrm{gm} / 1$ sodium carbonate and dyeing further for a period of $60 \mathrm{~min}$. Application of (vinyl salphone) Remazol blue R reactive dye on unmodified jute was accomplished at a material: liquor ratio of 1:20 at $60 \mathrm{oC}$ employing $50 \mathrm{gm} / 1$ glouber salt and $10 \mathrm{gm} / 1$ sodium carbonate. Dyeing was done for a period of $60 \mathrm{~min}$. Dyeing was commonly commenced at $30 \mathrm{oC}$ for application of all the dyes as mentioned above on unmodified jute.

Dyeing of sericin modified jute fabric with reactive dye following modified dyeing method: Dyeing of sericin modified jute was commenced at $30 \mathrm{oC}$ at a material: liquor ratio 1:20 with a starting $\mathrm{pH}$ in the range of 4 to 7 as specified employing drop wise addition of different doses of formic acid. $\mathrm{pH}$ of the dye bath was, subsequently brought to 10 to 12 by the addition of sodium carbonate after $25 \mathrm{~min}$ of dyeing. After addition of sodium carbonate for fixation of reactive dyes used in this study, the dyeing was continued for further $60 \mathrm{~min}$. Fixation temperatures kept for reactive dyes with dichlorotriazenyl, monochlorotriazenyl and vinyl sulphone reactive groups were $30 \mathrm{oC}, 80 \mathrm{oC}$ and $60 \mathrm{oC}$ respectively. The dye bath did not contain salt during application of reactive dye unless otherwise specified. The dyed fabrics were thereafter soap washed $(80 \mathrm{oC})$, hot washed, cold washed and finally dried in air. For assessment of fixation of reactive dyes, sericin modified dyed jute fabrics were extracted further with 50\% V/V DMF-water mixture in a Soxhlet apparatus for 30 min, washed with water and air dried. Exhaustion and fixation of reactive dyes were determined by taking dyes present in exhaust liquor, wash liquor and Soxhlet extract appropriately into consideration. The dye in each of the above liquor was estimated colourmetrically employing a U-2000 Hitachi UV-Vis spectrophotometer.

Estimation of percentage exhaustion and fixation of reactive dye: The exhaustion (dye uptake) of different reactive dyes as specified from their aqueous solutions to different specified substrates during application was estimated from the difference of initial concentration of dye solution taken from the dye bath at the start of dyeing and concentration of dye solution in the dye bath just before addition of sodium carbonate in the dyeing process described earlier. The difference was expressed as percentage of initial concentration in each case. The concentration of colouring substance in the test solution was obtained from the absorbance value of the later with the help of calibration curve previously constructed in a U2910 UV visible 
absorbance spectrophotometer, HITACHI, Japan. The calibration curve was constructed using the absorbance value of the standard solutions measured in the same spectrophotometer. Five standard solutions were prepared (such as $0.01 \%, 0.02 \%$, $0.04 \%, 0.06 \%$ and $0.08 \%$ ) by dissolving $0.1 \mathrm{gm}$ of reactive dye in $100 \mathrm{ml}$ of water and subsequently diluting the prepared solution to different appropriate level.

For estimation of fixation of reactive dye in different specified substrates the dyed substrates were extracted with $50 \%$ V/V DMF-water mixture in a Soxhlet apparatus for 30 minutes, washed with water and air dried. Fixation of reactive dyes on those substrates was thereafter calculated from the difference in quantity of dye present in the dye bath at the start of dyeing and the total quantity of dye left in the dye bath, aqueous wash liquor and in DMF-water mixture. The quantity of dye in each of such solutions was calculated by taking into consideration the concentration of the respective solutions measured spectophotometrically following the method described earlier and the volume of each of such individual solutions. For measuring dye concentration in the soap solution a separate calibration curve was constructed using 5 standard solutions prepared by dissolving requisite amount of dye in $5 \mathrm{~g} / \mathrm{l}$ soap solution following a procedure described above.

Determination of weight gain: For the determination of weight gain upon modification of jute fabric initial dry weight of unmodified fabrics (W2) were recorded. Then the modified fabric samples were soap washed following ISO II method as detailed before. The washed fabric samples were then dried to a constant weight (W1) at 100oC. The weight gain (\%) was calculated on the basis of initial dry weight (W2) using the following relationship:[6][7]

Weight gain $(\%)=\{(\mathrm{W} 1-\mathrm{W} 2) / \mathrm{W} 2\} \times 100$.

Measurement of K/S: Dye receptivity of unmodified and modified jute fabrics were estimated in terms of K/S value (Kubelka Munk - function) [2]. The value is based on measuring the reflectance of each dyed fabric samples at the respective wave length of maximum absorption $(\lambda \max )$ in a Maccbeth 2020- plus reflectance spectometer and converting the reflectance value to (Kubelka Munk - function) K/S as detailed below using the appropriate formula and relevant software attached to the computer aided equipment, following standard procedures.[6][7]

$\mathrm{K} / \mathrm{S}=(1-\mathrm{R} \lambda) 2 / 2 \mathrm{R} \lambda$

Where, $\mathrm{K}=$ coefficient of absorption

$\mathrm{S}=$ coefficient of scattering

$\mathrm{R} \lambda=$ reflectance of the substrate at $\lambda$ wave length

Assessment of colour fastness to washing: Colour fastness to washing of sample jute fabrics (modified/unmodified) dyed with reactive dyes were assessed in a launder-o-meter obtained from Mag, China according to a method prescribed in ISO 105 C06. [6][7]

Assessment of colour fastness to light: Colour fastness to light of selected jute fabrics (modified/unmodified) dyed with reactive dyes were assessed on a Mercury Bulb Tangsten Filament (MTBF) light fastness tester following a method prescribed in ISO: 105 B02.[6][7]

Assessment of colour fastness to rubbing: Colour fastness to rubbing of sample jute fabrics (modified/unmodified) dyed with reactive dyes were determined employing a crock meter developed by BTRA following the method prescribed in ISO: 105 $\mathrm{X} 12 .[6][7]$

Measurement of tensile properties of unmodified and modified jute fabrics: The tenacity of selected samples from unmodified and modified jute fabrics were measured in an Instron tensile testing machine 4411, Instron, USA, according to a method prescribed by ASTM D 5034.[6][7]

Determination of moisture regain values of modified and unmodified jute fabrics: Moisture regain values of selected samples were assessed following a method prescribed in ASTM D 2495-07. The results given are the average of 10 tests done for each sample.

Infrared (IR) spectroscopy: Infrared spectra of unmodified and selectively modified jute samples were obtained following the $\mathrm{KBr}$ pellet technique as detailed elsewhere, using a Bomem FTIR spectrometer of ABB Analytical Measurements (formerly Bomem Inc.), Canada.[6][7]

Estimation of nitrogen content: Quantitative determination of organic nitrogen content in unmodified and different specified sericin modified samples were done by Kjeldahl digestion method following a procedure prescribed in ASTM E258-07 (2015).

\section{RESULTS AND DISCUSSION}

Effect of variation of sericin concentration on the properties of jute fabric: Tables 1 shows the effect of application of degumming extract (sericin) on jute fabrics expressed in terms of weight of sericin on weight of 100 gm of jute fabric following a pad-dry-cure technique. It is evident from the figures 1 and 2 that with increase in dose levels of sericin, weight gain and nitrogen content of jute fabrics follow a common increasing trend. Increase in the degree of esterification of cellulose chain in jute via incorporated amino acid moieties, by application of increasing dose levels of trisodium citrate esterification catalyst, resulted in higher weight gain and nitrogen content. However, after treatment of jute with sericin in absence of any catalyst, very low weight gain and nitrogen content were achieved. This indicates that the potential of amino acid of sericin fraction of silk to self catalyse the esterification process for lignocellulosic fibre materials is simply marginal. The tenacity of jute fabric, however, followed a common decreasing trend with increasing does levels of sericin as shown in 
tables 1. Such marginal reduction of tenacity of jute fabrics after modification with sericin, is the consequence of hydrolytic degradation of lignocelilosic fibre structure occurred during post modification curing at an elevated temperature.

Table 1 Effect of application sericin on the properties of jute

\begin{tabular}{|l|l|l|l|l|}
\hline $\begin{array}{l}\text { Jute modified } \\
\text { with }\end{array}$ & $\begin{array}{l}\text { Trisodium Trisodium } \\
\text { citrate used }(\%)\end{array}$ & Weight gain $(\%)$ & $\begin{array}{l}\text { Nitrogen content } \\
(\%)\end{array}$ & Tenacity (N/cm) \\
\hline None & - & - & 0.94 & $109[1.46]^{*}$ \\
\hline $1 \%$ sericin & 1.75 & 0.96 & 1.11 & $108[1.52]^{*}$ \\
\hline $2 \%$ sericin & 3.5 & 1.91 & 1.30 & $107.01[1.55]^{*}$ \\
\hline $3 \%$ sericin & 5.25 & 2.83 & 1.41 & $105.86[1.48]^{*}$ \\
\hline $5 \%$ sericin & 8.75 & 4.60 & 1.83 & $105[1.51]^{*}$ \\
\hline $8 \%$ sericin & 14 & 7.60 & 2.60 & $104.25[1.49]^{*}$ \\
\hline $12 \%$ sericin & 21 & 11.52 & 4.35 & $102.24[1.60]^{*}$ \\
\hline $8 \%$ sericin & - & 0.93 & 1.05 & $104.84[1.41]^{*}$ \\
\hline
\end{tabular}

Note: $*$ The data given in the parenthesis refer to the $\mathrm{cv} \%$ of the corresponding property parameters

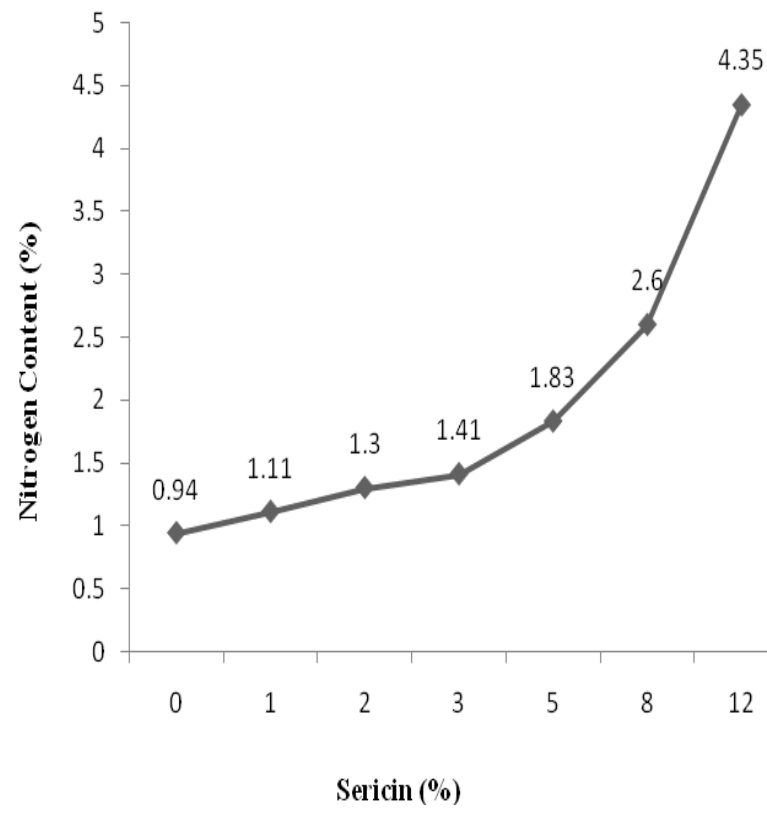

Fig 1 Effect of application of different dose levels of sericin on nitrogen content $(\%)$ of jute fabric

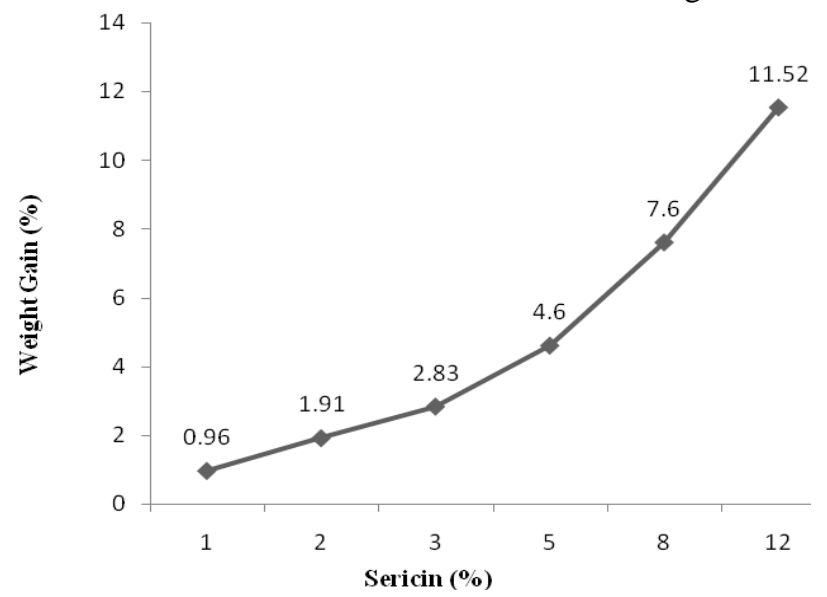

Fig 2 Effect of application of different dose levels of sericin on weight gain (\%) of jute fabric 
IR analysis of jute fabrics modified with sericin: Figure 3 shows IR spectra of (a) unmodified bleached jute and (b) bleached jute modified with sericin in presence of trisodium citrate as esterification catalyst following pad-dry-cure technique. Broad absorption bands over 3000 to $3500 \mathrm{~cm}-1$ commonly obtained for both the unmodified and sericin modified jute fabrics are evidently characteristic of hydrogen bonded hydroxyl stretching vibration. Other common notable absorption bands obtained for jute as shown in both the spectra of figure 3, in the region of $1560 \mathrm{~cm}-1$ to $1570 \mathrm{~cm}-1$ appearing in different intensities, are characteristics of carboxylate anion vibrations. Sericin modification of jute resulted in intensification of the absorption band at $1740 \mathrm{~cm} \mathrm{-1.} \mathrm{This} \mathrm{is} \mathrm{characteristic} \mathrm{of} \mathrm{ester} \mathrm{stretching} \mathrm{vibration} \mathrm{as} \mathrm{evident} \mathrm{from} \mathrm{spectrum} \mathrm{(b)} \mathrm{of} \mathrm{figure} \mathrm{3.} \mathrm{Also} \mathrm{in}$ spectrum (b) a notable absorption band at $1610 \mathrm{~cm}-1$, characteristic of $\mathrm{NH}$ stretching of amine, indicates incorporation of amino acid residues of sericin fraction into jute. Trisodium citrate when used as esterification catalyst for sericin modification of jute, enhances incorporation of amino acids into jute in consequent to establishment of ester linkages between the carboxyl groups of amino acid moieties of sericin and hydroxyl groups of jute cellulose.

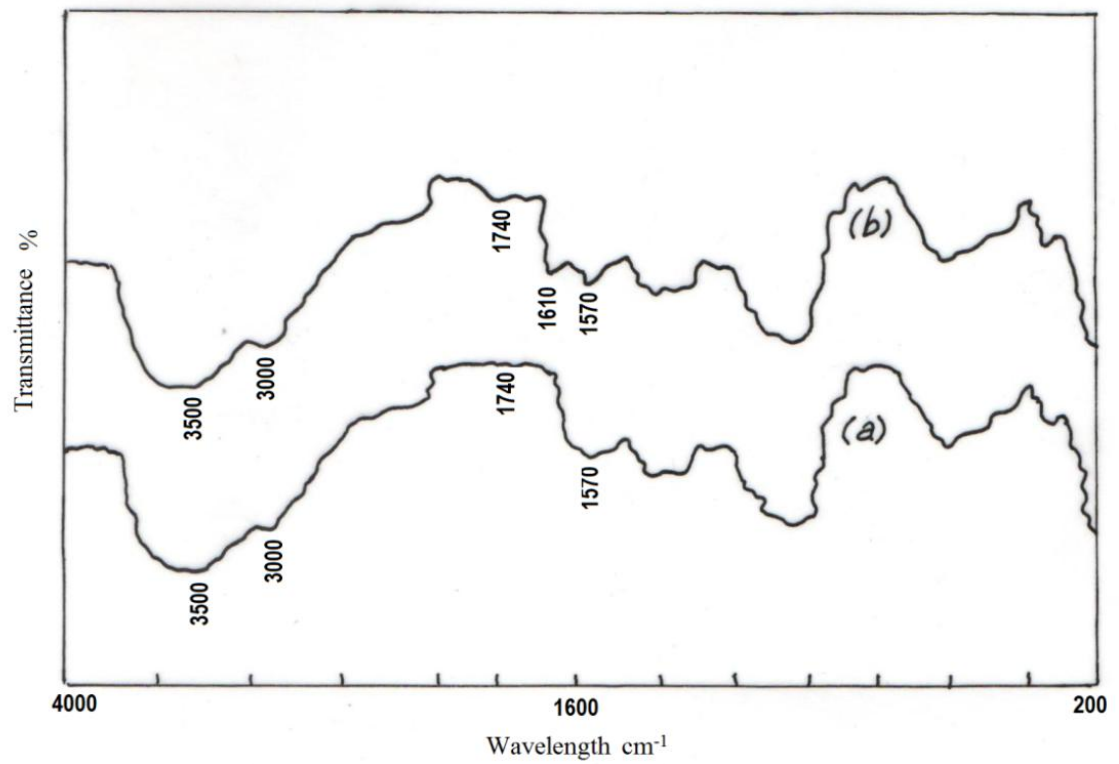

Fig 3 Infrared spectra of (a) jute and (b) jute modified with sericin fraction of silk

Effect of variation of dye bath $\mathrm{pH}$ on exhaustion of reactive dyes in sericin modified jute fabric: It is established now that an acidic dye bath at the start of dyeing during colouration of wool with reactive dye, distinctly favours higher incorporation of dyes in the protein substrate owing to strong mutual attraction between protonated positively charged protein fibre and negatively charged reactive dye [14]. Keeping such reports of application of reactive dye on wool fibre in view, effects of variation of starting dye bath $\mathrm{pH}$ for applications of different reactive dyes on sericin modified jute have been studied.

Experimental runs with different $\mathrm{pH}$ levels (range 4 to 7 ) and different levels of percentage nitrogen contents in modified jute substrates resulted in varying levels of exhaustion of reactive dyes in sericin modified jute. Results are presented by tables 2 to 4.

Table 2 Exhaustion of Procion red M5B in Sericin modified jute

\begin{tabular}{|c|c|c|c|c|c|c|c|c|}
\hline \multirow[t]{2}{*}{$\mathrm{pH}$} & \multicolumn{8}{|c|}{ Nitrogen Content (\%) } \\
\hline & 0.94 & 1.11 & 1.3 & 1.41 & 1.83 & 2.6 & 4.35 & \\
\hline 4 & 81.2 & 87 & 89.2 & 92 & 94.4 & 98 & 97 & Exhaustion \% \\
\hline 5 & 78.8 & 85.3 & 87.3 & 90.3 & 93.2 & 96.2 & 95.8 & \\
\hline 6 & 77 & 83.2 & 86.2 & 88.4 & 91.5 & 93.4 & 94 & \\
\hline 7 & 75.4 & 82 & 84.6 & 87 & 89.2 & 92.2 & 93.2 & \\
\hline
\end{tabular}

Table 3 Exhaustion of Procion yellow H4C in Sericin modified jute

\begin{tabular}{lllllllll}
\hline $\mathrm{pH}$ & \multicolumn{2}{l}{ Nitroge Content (\%) } & & & & \\
& 0.94 & 1.11 & 1.3 & 1.41 & 1.83 & 2.6 & 4.35 & \\
4 & 78.8 & 84.2 & 87.4 & 91.5 & 95.4 & 98.1 & 97.6 & Exhaustion \% \\
5 & 77 & 82 & 85.6 & 88.4 & 93 & 96.3 & 96 & \\
6 & 75.3 & 79 & 83.5 & 86 & 90.7 & 93.4 & 93.7 & \\
\hline
\end{tabular}




\begin{tabular}{lllllllll}
\hline 7 & 72.4 & 77.4 & 81 & 84.3 & 88 & 91 & 92 & \\
\hline \multicolumn{7}{l}{ Table 4 Exhaustion of Remazol blue R in Sericin modified jute } \\
\hline $\mathrm{pH}$ & \multicolumn{1}{l}{ Nitrogen Content (\%) } \\
& 0.94 & 1.11 & 1.3 & 1.41 & 1.83 & 2.6 & 4.35 & \\
4 & 75 & 81.3 & 85 & 89.4 & 93.7 & 96 & 95.5 & Exhaustion \% \\
5 & 74 & 79.2 & 83.2 & 87 & 92.6 & 94.3 & 94 & \\
6 & 72.6 & 76 & 81.3 & 85.5 & 90 & 92.2 & 91.7 & \\
7 & 69 & 73.2 & 79.3 & 82 & 86.6 & 89.3 & 90 & \\
\hline
\end{tabular}

In order to understand the effect of variation of these two independent variables on exhaustion percentages of all three reactive dyes used in the study (Chlotrotriazine containing reactive dyes Procion red M5B and Procion yellow H4C, vinyl sulphone containing reactive dye Remazol blue R), bar charts for each experimental set have been prepared and shown in figures 4 to 6.

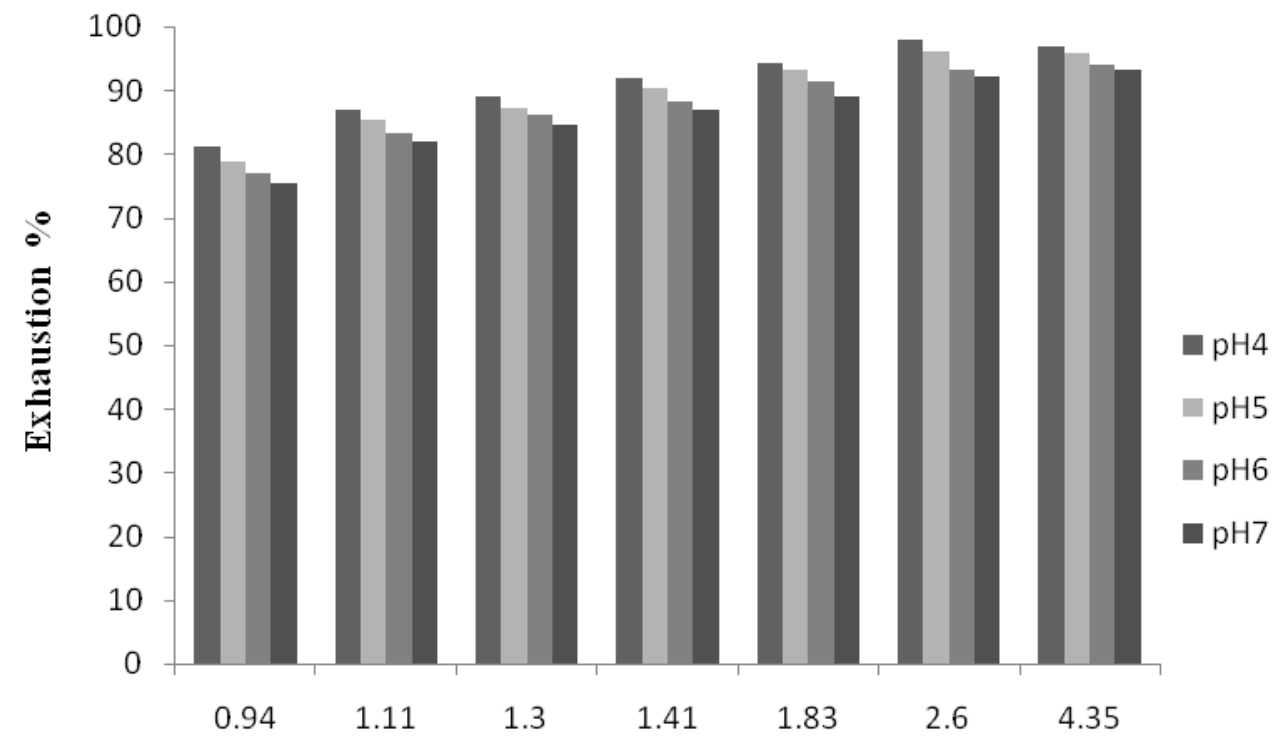

Nitrogen content $\%$

Fig 4 Bar chart showing exhaustion of Procion red M5B w.r.t. nitrogen content in sericin modified jute fabric at different pH level of dye bath 


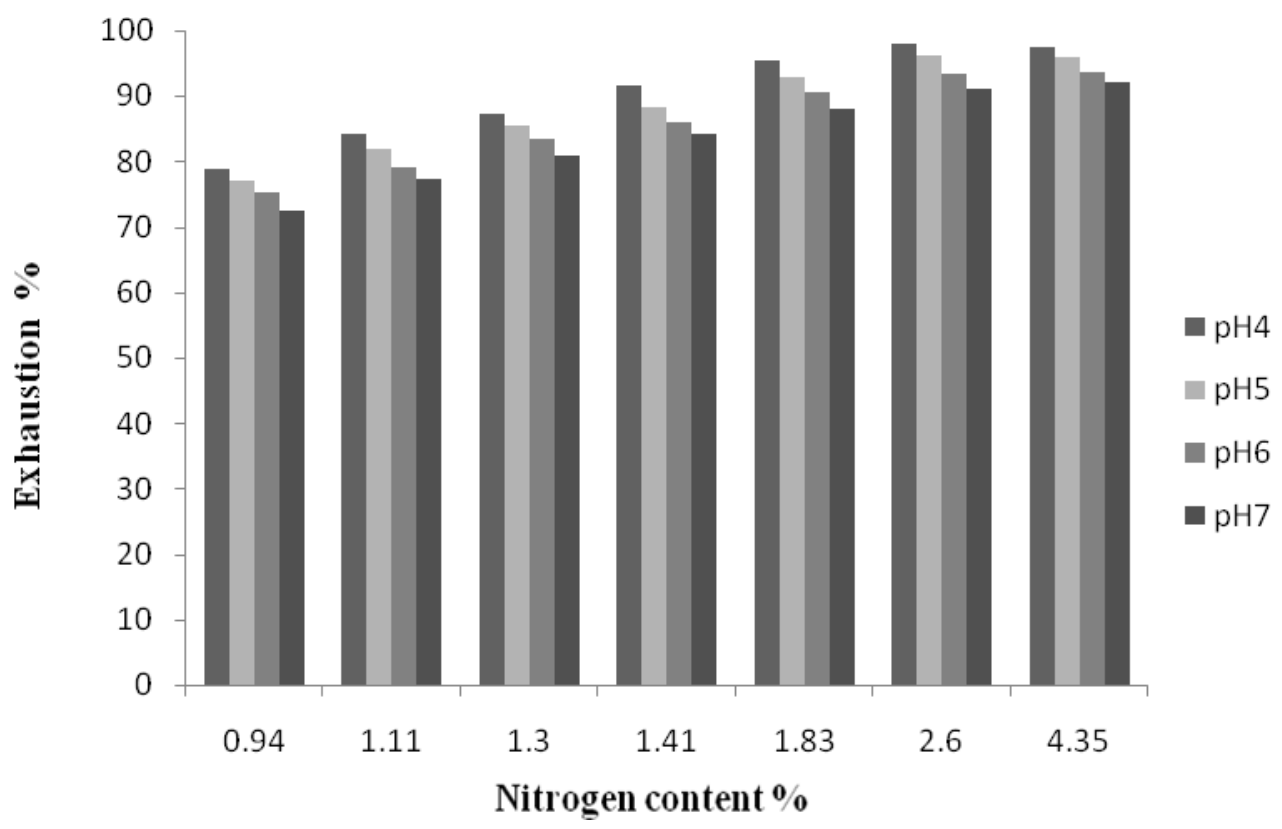

Fig 5 Bar chart showing exhaustion of Procion yellow H4C w.r.t. nitrogen content in sericin modified jute fabric at different $\mathrm{pH}$ level of dye bath

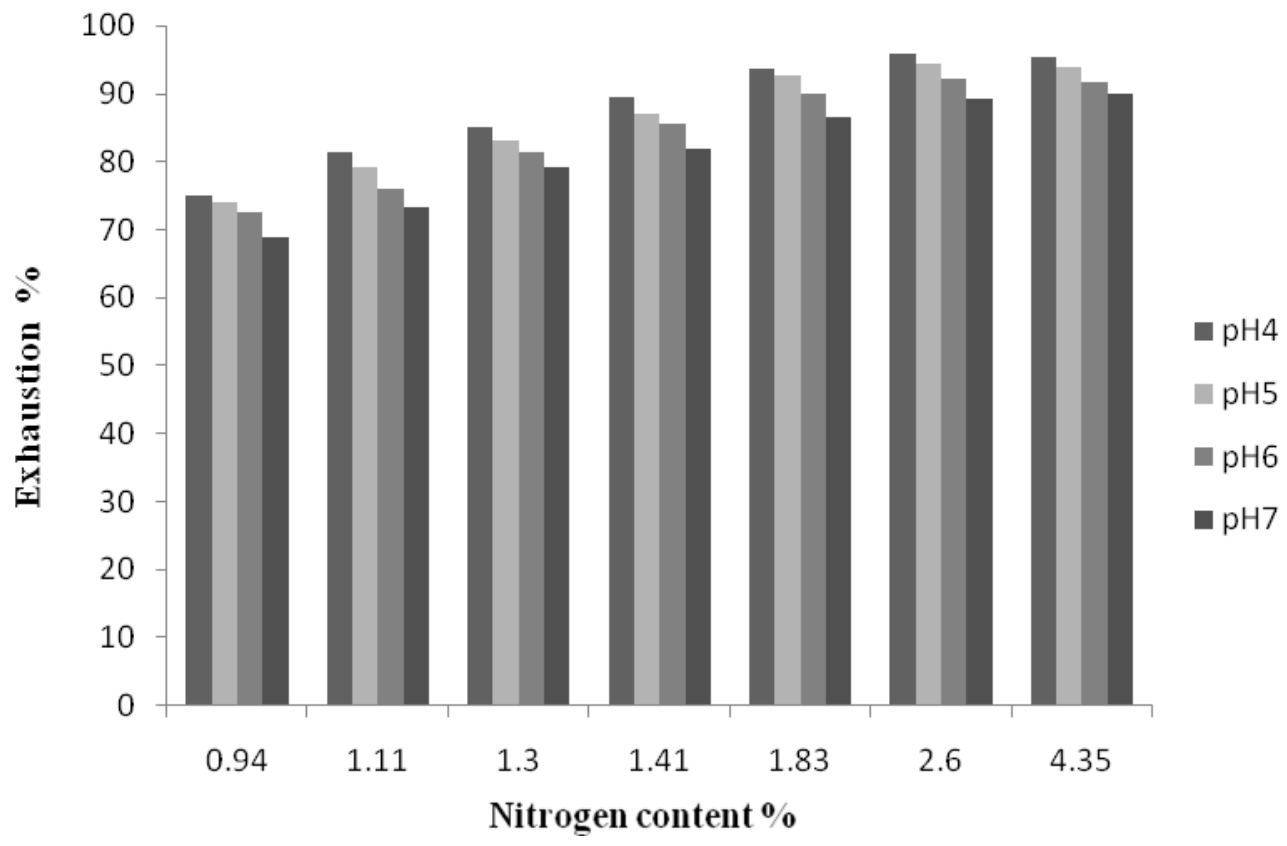

Fig 6 Bar chart showing exhaustion of Remazol blue R w.r.t. nitrogen content in sericin modified jute fabric at different $\mathrm{pH}$ level of dye bath

Results show that, with decrease in dye bath $\mathrm{pH}$, exhaustion of reactive dyes follow a common increasing trend for sericin modified jute fabrics. This indicates that the protonation of amino acid modified jute favours increase in reactive dye uptake. Also, exhaustion of all the reactive dyes considered in the present study (Tables 2 to 4 and Figures 4 to 6) reach their respective maximum at a common dye bath $\mathrm{pH}$ of 4 . The appreciable exhaustion observed for all three colourants at starting dye bath $\mathrm{pH}$ of 4 are considered to be of practical significance for dyeing of lingo cellulosic fibres such as jute. Dye-fibre attraction between reactive dyes and amino acid modified systems, in absence of salt, is expected to depend chiefly on ionic attraction between negatively charged reactive dyes and electron deficient protonated amino groups duly bound to jute substrate via ester linkage. Such exhaustion pattern ultimately leads to improved levels of dye transfer into the sericin modified lingo cellulosic substrates from an aqueous dye bath. Also, an increasing trend of exhaustion is observed with increasing dose levels of sericin for modification, as is evident from the tables 2 to 4 and figures 4 to 6 . However, a final, 
almost levelling off trend for exhaustion of reactive dyes appeared for application of sericin just beyond $8 \%$ level; which corresponds to sericin modified jute sample having $2.60 \%$ nitrogen content, as shown in tables 2 to 4 and figures 4 to 6. [16] The levelling off trend observed for higher concentration of sericin application is due to the physical barrier offered by the grafted-on amino acid moieties to the approaching dye anions from the aqueous solution phase during dyeing.

Effect of variation of dye bath $\mathrm{pH}$ on fixation of reactive dyes on sericin modified jute fabric: Experimental runs with varying $\mathrm{pH}$ values during fixation (range 9 to 12) and different levels of percentage nitrogen contents in modified fabrics affected the fixation of reactive dyes on sericin modified jute substrate. Results are given in tables 5 to 7.

Table 5 Fixation of Procion red M5B in Sericin modified jute

\begin{tabular}{|c|c|c|c|c|c|c|c|c|}
\hline \multirow[t]{2}{*}{$\overline{\mathrm{pH}}$} & \multicolumn{8}{|c|}{ Nitrogen Content (\%) } \\
\hline & 0.94 & 1.11 & 1.3 & 1.41 & 1.83 & 2.6 & 4.35 & \multirow{5}{*}{ Fixation $\%$} \\
\hline 9 & 71.2 & 75.5 & 82.3 & 87.3 & 91 & 93.2 & 92.6 & \\
\hline 10 & 74.3 & 79 & 84.5 & 90 & 93.5 & 95 & 95 & \\
\hline 11 & 76.4 & 80.5 & 86 & 91.4 & 95 & 97 & 96.5 & \\
\hline 12 & 73 & 78 & 83.2 & 88.2 & 93 & 94.2 & 93.6 & \\
\hline \multirow[t]{2}{*}{$\mathrm{pH}$} & \multicolumn{7}{|c|}{ Nitrogen Content (\%) } & \multirow{6}{*}{ Fixation $\%$} \\
\hline & 0.94 & 1.11 & 1.3 & 1.41 & 1.83 & 2.6 & 4.35 & \\
\hline 9 & 67.5 & 75.3 & 83.3 & 86 & 88.5 & 90 & 91 & \\
\hline 10 & 70.2 & 77 & 84.2 & 88.6 & 91.6 & 93.2 & 93 & \\
\hline 11 & 72 & 80.5 & 87 & 92.2 & 94.3 & 96.1 & 95.6 & \\
\hline 12 & 70.9 & 78 & 83.8 & 87.6 & 92.5 & 93.6 & 93 & \\
\hline \multicolumn{9}{|c|}{$\begin{array}{l}\text { Table 7 Fixation of Remazol blue R in Sericin modified jute } \\
\mathrm{pH}\end{array}$} \\
\hline & 0.94 & 1.11 & 1.3 & 1.41 & 1.83 & 2.6 & 4.35 & \multirow{5}{*}{ Fixation $\%$} \\
\hline 9 & 65 & 71.2 & 77 & 80 & 84.5 & 87.2 & 86 & \\
\hline 10 & 67.3 & 73 & 78.3 & 84.2 & 86.3 & 92.7 & 92.2 & \\
\hline 11 & 68.8 & 74.2 & 82.3 & 86.5 & 90.2 & 95 & 94.2 & \\
\hline 12 & 70 & 74.6 & 80.2 & 85.4 & 88 & 93 & 92 & \\
\hline
\end{tabular}

In order to understand the effect of variation of the above two independent variables on fixation percentages achieved for all three reactive dyes used in the study (Chlotrotriazine containing reactive dyes Procion red M5B and Procion yellow H4C, vinyl sulphone containing reactive dye Remazol blue R), bar charts for each experimental set have been prepared and shown in figures 7 to 9 . 


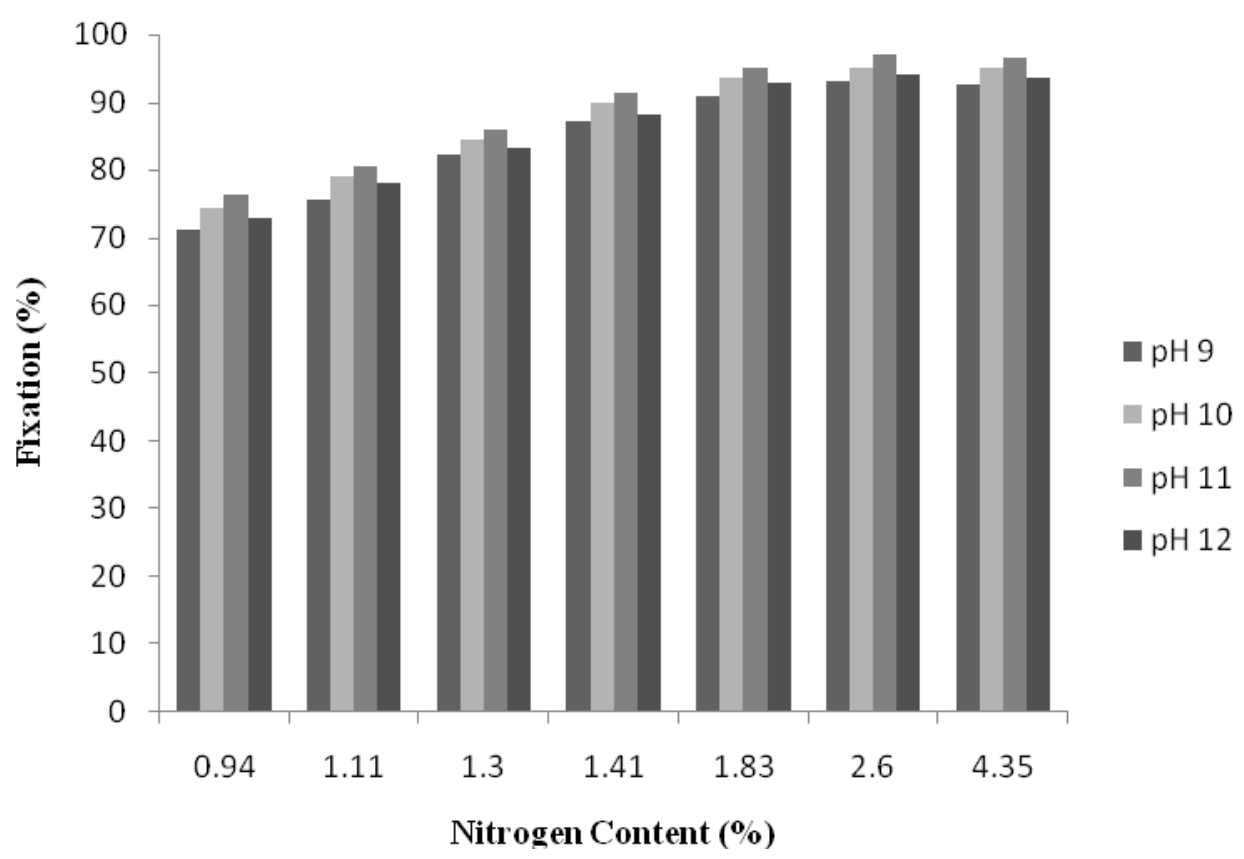

Fig 7 Bar chart showing fixation of Procion red M5B w.r.t. nitrogen content in sericin modified jute fabric at different pH level of dye bath

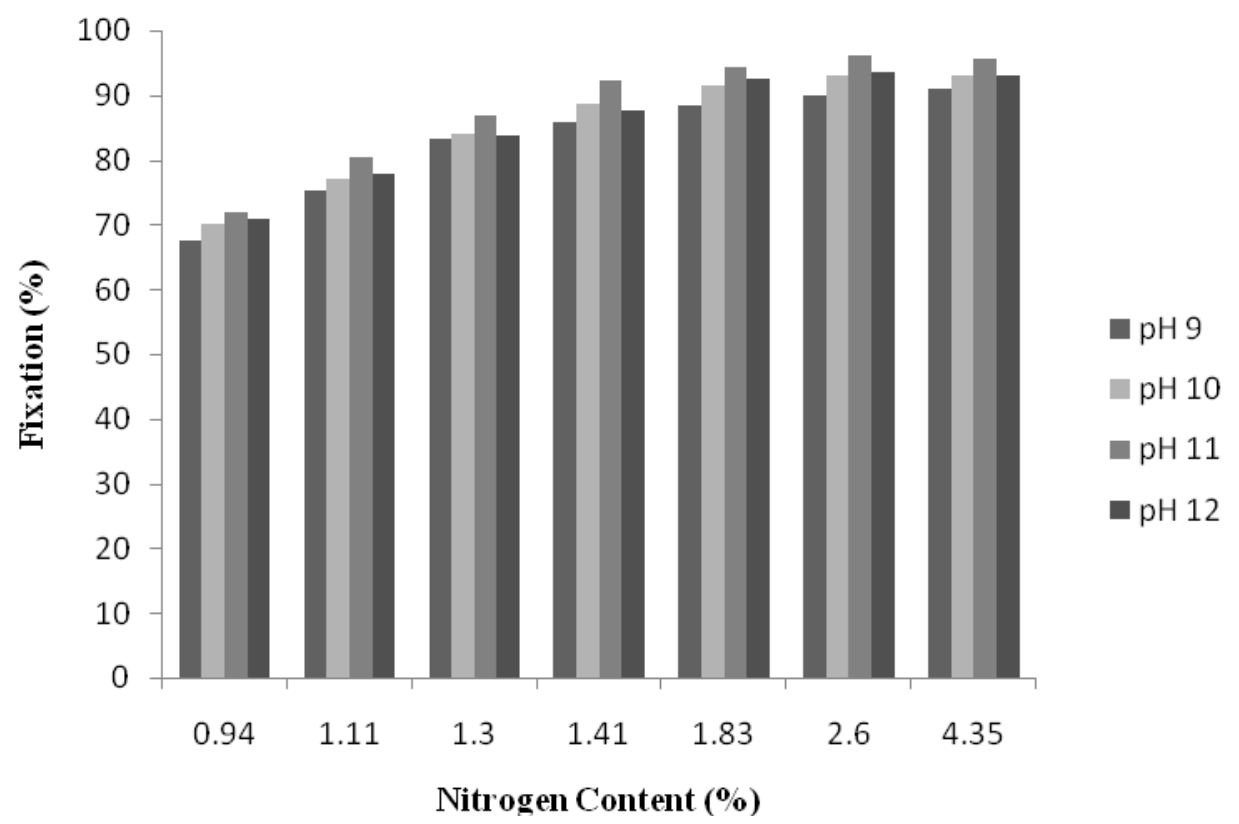

Fig 8 Bar chart showing fixation of Procion yellow H4C w.r.t. nitrogen content in sericin modified jute fabric at different $\mathrm{pH}$ level of dye bath 


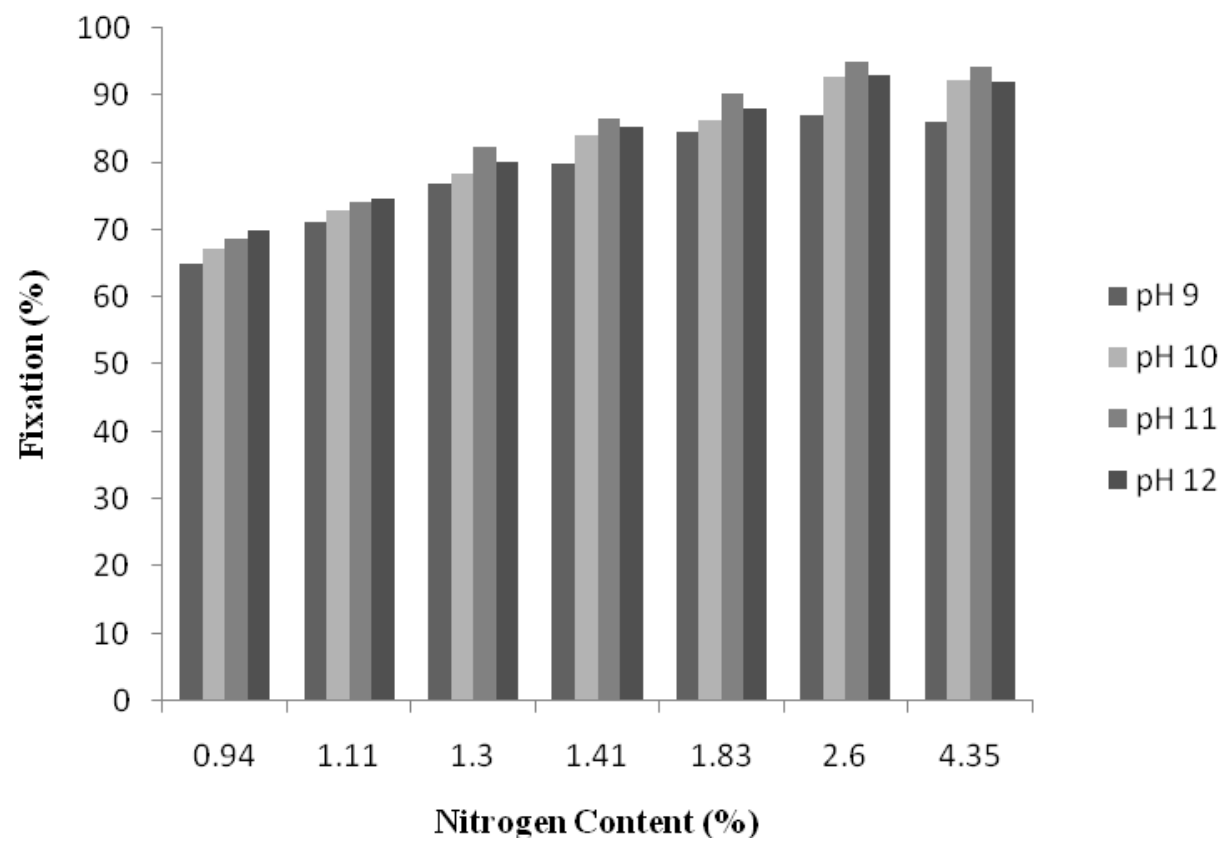

Fig 9 Bar chart showing fixation of Remazol blue R w.r.t. nitrogen content in sericin modified jute fabric at different pH level of dye bath

Results from the above studies show that fixation of all the dyes follow a common increasing trend with increase in fixation $\mathrm{pH}$ of the dye bath, reaching the maximum at a common dye bath $\mathrm{pH}$ of 11 , for all jute samples modified with varying dose levels of sericin. Similar observation of establishment of dye fibre bond between primary hydroxyl group of cellulose and reactive dyes at $\mathrm{pH}$ level 10.5, have been also reported by Lewis (Lewis D. , 1993).

From the above study it is observed that fixation of all the reactive dyes follow a common increasing trend with increase in nitrogen content of the sericin modified substrates. Fixation percentages of dyes reach the maximum level for $2.60 \%$ nitrogen content for even different fixation $\mathrm{pH}$ levels considered in the present study. This corroborates with the exhaustion patterns of reactive dyes achieved for jute samples described earlier. Increasing level of incorporation of amino acid into jute via esterification evidently caused higher extent of fixation of reactive dyes at all $\mathrm{pH}$ levels of fixation. The fixation of reactive dyes in quantitative sense, therefore, appears to be dependent on initial absorption of reactive dyes on sericin modified jute substrate.

Comparative property parameters of reactive dyed unmodified jute fabric and jute fabric prior modified with sericin fraction of silk: A comparison of property parameters of reactive dyed jute modified with sericin and reactive dyed unmodified jute is shown in the tables 8 . Figures from the table show prior sericin modification of jute led to very high level of fixation of vinyl sulphone and chlorotriazine reactive dyes on jute without adversely affecting colour fastness to light, rubbing and wash. Higher fixation levels of reactive dyes achieved in jute substrate are validated by enhancement of K/S values to notable higher levels.

Table 8 Comparison of some important functional properties of reactive dyed unmodified jute and reactive dyed sericin modified jute

\begin{tabular}{|c|c|c|c|c|c|c|c|c|c|c|}
\hline \multirow{3}{*}{$\begin{array}{l}\text { Jute } \\
\text { modified } \\
\text { with }\end{array}$} & \multirow{3}{*}{$\begin{array}{l}\text { Name of the } \\
\text { dye applied }\end{array}$} & \multirow{3}{*}{$\begin{array}{l}\text { Exhausti } \\
\text { on } \\
(\%)\end{array}$} & \multirow{3}{*}{$\begin{array}{l}\text { Fixati } \\
\text { on } \\
(\%)\end{array}$} & \multirow{3}{*}{$\begin{array}{l}\mathrm{K} / \mathrm{S} \lambda \\
\max \end{array}$} & \multicolumn{5}{|c|}{ Colour fastness to } & \multirow{3}{*}{$\begin{array}{l}\text { Moisture } \\
\text { regain } \\
(\%)\end{array}$} \\
\hline & & & & & \multicolumn{3}{|l|}{ Washing } & \multirow{2}{*}{ Rubbing } & \multirow{2}{*}{ Light } & \\
\hline & & & & & $\begin{array}{l}\text { Change } \\
\text { of shade }\end{array}$ & $\begin{array}{l}\text { Stain } \\
\text { on } \\
\text { cotton }\end{array}$ & $\begin{array}{l}\text { Stain } \\
\text { on } \\
\text { wool }\end{array}$ & & & \\
\hline None & $\begin{array}{l}\text { Procion } \\
\text { red M5B }\end{array}$ & 81.2 & 76.4 & 13.32 & 5 & 5 & $4-5$ & 5 & 5 & $\begin{array}{l}16 \\
{[1.27]^{*}}\end{array}$ \\
\hline $\begin{array}{l}8 \% \\
\text { sericin }\end{array}$ & Do & 98 & 97 & 17.64 & 5 & 5 & 5 & 5 & 5 & $\begin{array}{l}19 \\
{[1.08]^{*}}\end{array}$ \\
\hline None & $\begin{array}{l}\text { Procion } \\
\text { yellow H4C }\end{array}$ & 78.8 & 72 & 11.82 & 5 & 5 & 5 & 5 & 5 & $\begin{array}{l}16 \\
{[2.38]^{*}}\end{array}$ \\
\hline $8 \%$ & Do & 98.1 & 96.1 & 13.54 & 5 & 5 & 5 & 5 & 5 & 19 \\
\hline
\end{tabular}




\begin{tabular}{|l|l|l|l|l|l|l|l|l|l|l|}
\hline sericin & & & & & & & & & & {$[1.95]^{*}$} \\
\hline None & $\begin{array}{l}\text { Remazol } \\
\text { blue R }\end{array}$ & 75 & 68.8 & 15.71 & 5 & 5 & $4-5$ & 5 & $6-7$ & $\begin{array}{l}16 \\
{[1.85]^{*}}\end{array}$ \\
\hline $\begin{array}{l}8 \% \\
\text { sericin }\end{array}$ & Do & 96 & 95 & 18.25 & 5 & 5 & $4-5$ & 5 & $6-7$ & $\begin{array}{l}18.5 \\
{[2.21]^{*}}\end{array}$ \\
\hline
\end{tabular}

Note: *The data given in the parenthesis refer to the cv $\%$ of the corresponding property parameters

On overall assessment, reactive dyed sericin modified jute fabrics appear to be superior to reactive dyed unmodified jute fabrics in respect of fixation of reactive dyes and moisture regain for achieving comparable colour fastness properties, after dyeing with reactive dyes, in total absence of salt.

\section{CONCLUSIONS}

Jute fabrics were modified with hydrolysed sericin fraction of silk in presence of trisodium citrate as the esterification catalyst following a pad- dry- cure technique. Optimum dose level of sericin was found to be $8 \%$. Optimum dose level of trisodium citrate as esterification catalyst was found out to be $12 \%$. Padding of the fabrics were done with aqueous solution of sericin to $100 \%$ wet pick up at room temperature. Padded fabrics were dried at $95 \mathrm{oC}$ for 5 minutes followed by curing at 140 o $\mathrm{C}$ for 5 minutes.

IR spectroscopy and estimation of nitrogen content of the sericin modified jute substrates indicated the incorporation of amino acid residues of sericin fraction of silk in the polymeric chains of jute via establishment of ester linkages between carboxylic acid groups of amino acid moiety of sericin and hydroxyl groups of jute cellulose.

Prior modification of jute with $8 \%$ sericin fraction of silk in presence of $14 \%$ trisodium citrate as esterification catalyst makes jute fabrics aminated at an optimum level for attracting reactive dyes containing chlorotriazine and vinyl sulphone reactive groups from aqueous solution, for final dye exhaustion of more than $90 \%$ in total absence of salt.

Dyeing of sericin modified jute was best accomplished in absence of salt with a starting dye bath $\mathrm{pH}$ of 4 . The final $\mathrm{pH}$ level of 11 was found suitable for fixation of reactive dyes on modified jute substrates. High level of exhaustion of reactive dyes into jute substrates modified with sericin resulted into achievement of very high fixation level (more than 90\%) as well.

Higher exhaustion of reactive dyes in modified jute substrates with sericin, in complete absence of salt or electrolyte provides scope for mitigating salinity related pollution from the effluent generated from the reactive dyeing process.

Achievement of very high level of fixation of reactive dyes into jute substrates modified with sericin helps in reducing the level of unfixed colour in the residual dye bath after completion of dyeing. This reduces the risk of coloured effluent discharge in the environment.

Prior modification of jute fabrics with sericin fraction of silk followed by dyeing with reactive dyes also lead to most balanced improvement in the properties of dyed substrates in respect of moisture regain, colour fastness to wash, light and rubbing without significant loss of tenacity.

Application of chlorotriazine reactive dyes following the modified method used in the study also leads to significant saving of dyeing time of 30 minutes in a batch.

\section{REFERENCES}

[1] Blanchard E J (1988) Dyeability of crosslinked cationic cotton fabrics. Textile Chemist \& Colourist 20: 25

[2] Billmeyer F W, Saltzman M (1981) Principle of color tecnology. New York, Wiley

[3] Benz J (1961) The Hydrolysis of Reactive Dyeings. Colouation Technology 77: 734-740

[4] Bairagi N, Gulrajani M L, Deopura B L, Shrivastava A (2005) Dyeing of N-modified viscose rayon fibres with reactive dyes. Colouration Technology $121: 113-120$

[5] Chattopadhyay D P (2001) Cationisation of cotton for low salt or salt free dyeing. Indian Journal of Fibre \& Textile Reasearch 26: 108-115

[6] Das D, Bakshi S, Bhattacharya P (2014) Dyeing of sericin-modified cotton with reactive dyes. Journal of The Textile Institute 105: 314-320

[7] Das D, Bakshi S, Bhattacharya P (2016) Dyeing of EDTA-modified cotton with reactive dyes. Clothing \& Textile Research Journal 34: 196-206

[8] Das D, Datta D B, Bhattacharya P (2014) Simultaneous dyeing and finishing of silk fabric with natural colour and itaconic acid. Clothing and textile research journal 32: 93-106

[9] Das D, Munshi R (2006) Finishing of cotton with methacrylic acid under thermal treatment. Journal of The Textile Institute 97: 519

[10] Galloway L D (1939) Minimum moisture regain for the development of microorganisms on jute. Journal of The Textile Institute 30: 27-30

[11] Ghosh P, Das D, Samanta A K (1995) Modification of jute with citric acid. Journal of polymer materials 12: 297-305

[12] Ghosh P, Das D (2000) Modification of cotton with acrylic acid in presence of K2S2O8 \& NH2PO4 under thermal treatment. European Polymer Journal 36: 2511

[13] Kundu B C, Basak K C, Sirkar P B (1959) Jute in India. Indian Central Jute Committee 1

[14] Lewis D M (1993) New possibilities to improve cellulosic fiber dyeing process with fiber reactive systems. Journal of the Society of Dyers and Colorists 109: 357

[15] Lewis D M (1999) Colouration in the next century. Rev. Prog. Colouration 29: 23

[16] Saha A K (2000) Improvement of functional properties of jute based composite by acrylonitrile pre treatment. Journal of Applied Polymer Sciences 78: 495-506 